\title{
Prólogo arameo y anotaciones hebreas de Alfonso de Zamora para una copia manuscrita del Targum a los Profetas encarga- da por la Universidad de Salamanca
}

Carlos Alonso Fontela *

Universidad Complutense de Madrid

\begin{abstract}
El ms. Or. 645, f. ${ }^{\circ}$ 110r (ol. Warner 65 F) de la Leiden University Library, además del borrador de un prólogo arameo a la obra de Targum escrito por Alfonso de Zamora hacia el año 1532 por encargo de la Universidad de Salamanca, contiene otras anotaciones del mismo autor que aquí se publican por primera vez y que también formaban parte del mismo encargo de copia de textos targúmicos. En el presente artículo, además de mejorar el texto arameo del prólogo ya publicado por Neubauer en 1895, se ofrece su traducción española por primera vez. Asimismo, se publica y traduce una anotación marginal que consiste en un borrador de las jaculatorias o doxologías (תפלות סופי הספרים) para los colofones parciales de los libros del Targum de Ezequiel, Oseas y Joel. Estos colofones parciales del ms. de Leiden coinciden con los pasados a limpio que se conservan en el manuscrito autógrafo de Alfonso de Zamora ms. M-3 (Est.-1, Cajón I-Núm. 2) de la Biblioteca Universitaria de Salamanca. Se explican otras anotaciones (el incipit de Isaías 57) que estropearon el folio, lo que dio lugar a que este fuese reutilizado como borrador por Alfonso de Zamora.
\end{abstract}

Palabras clave: Biblia Políglota Complutense; Cisneros; Pablo Coronel; Neubauer; Leiden.

Alonso de Zamora's Aramaic Prologue and Hebrew Notes for a Manuscript Copy of the Targum to Prophets Comissioned by the University of Salamanca. - Leiden University Library Ms. Or. 645, f. 110r (ol. Warner 65 F) contains, besides a draft for an Aramaic prologue to the work on Targum written by Alonso de Zamora $c a$. 1532, additional notes written by himself dealing with the comission he received to copying Targumic texts. The present article improves the edition of the Aramaic prologue, previously published by Neubauer (1895), offering a Spanish translation and the edition of the marginal notes, that contain a draft of the prayers (תפלות סופי (הספרים for the partial colophons of the books of Ezekiel, Hosea and Joel's Targums. These pa tial colophons in the Leiden Ms. coincide with the clean drafts by Zamora preserved in an autograph manuscript, Salamanca University Library Ms. M-3 (Est.-1, Cajón I-Núm. 2). An explanation concerning additional annotations (the incipit of Isaiah 57), that spoiled the folio, and led it to its being re-used by Alonso de Zamora as a draft.

Keywords: Complutense Polyglot Bible; Cisneros; Pablo Coronel; Neubauer; Leiden.

\footnotetext{
*calonsof@filol.ucm.es
} 
El manuscrito Leiden University Library, ms. Or. 645, f. 110r (olim Warner $65 \mathrm{~F}$ ) consiste en una única hoja en pergamino que, según Moritz Steinschneider ${ }^{1}$ contiene la הקדמת מלאכת התרגום שכתבתי למדינת שאלאמאנקה, Introductio [chaldaica] in opus Targum. La traducción castellana completa del texto hebreo sería: «Introducción [aramea] a la obra de Targum que escribí para la ciudad de Salamanca» ${ }^{2}$.

Steinschneider señalaba muy acertadamente que el autor de esta introducción sería, sin duda («sine dubio»), Alfonso de Zamora, e indicaba que a la vuelta de este folio se puede leer:

יום ג' כ"ח לחדש היברירו התחלתי מלאכת שאלמנקה שנת ל"ב ומספר שטות הדלת i. e. fer. III, 28 Februarii incepi opus Salamanca A. 32[1532] cet.

La traducción castellana completa del texto hebreo sería: 'El día martes, 28 de hebrero ${ }^{3}$, comencé la obra de Salamanca. Año de $<15>32$. El número de líneas por columna son [sic pro es] 31 en cada columna'.

${ }^{1}$ M. Steinschneider, Catalogus Codicum Hebraeorum Bibliothecae Academiae LugdunoBatavae (Lugduni Batavorum 1858), pág. 281.

${ }^{2}$ Este título hebreo, que ocupa la primera línea del folio, está subrayado. Su escritura es una cuadrada sefardí típica de Alfonso de Zamora. Está vocalizado, con la característica, y muy castellana, despreocupación de Alfonso de Zamora en distinguir entre qâmeș, pátạ̣ y hatạ pátaḥ ( haqdâmat mělék ket ha-târgum -sic con qâmeș en vez de pátah- še-kâtábtî li-mědînat Ša'lâ'mánqâh), y tiene una marca en forma de cuña que indica las letras que no son radicales, así como acentos tónicos en las palabras llanas lo que es característico de los textos hebreos y arameos de la Políglota Complutense (Cf. Biblia Políglota Complutense, tomo II, Prologus ad lectorem, f. ${ }^{\circ} 2 \mathrm{r}$. ... apice desuper...cum non sit littera substantialis..., y f.o $2 \mathrm{v}$ : [dicciones Hebraicae]... no $<n>$ habentes accentu $<m>$ in ultima (quae rarissime occurrunt) super syllabam ubi praedominatur accentus apice signarentur...), asî como de muchos manuscritos autógrafos de Alfonso de Zamora.

${ }^{3}$ En los documentos castellanos del s. XVI unas veces se usa «hebrero» y otras «febrero», pero el uso de «hebrero», que, aunque admitido, se considera hoy en día un arcaísmo, es característico de Alfonso de Zamora, quien usa exactamente la misma grafía היברירו en el colofón del ms. G-I-8 la Biblioteca del Real Monasterio del Escorial, f. $230 \mathrm{v}$, y en el colofón parcial del ms. BH 13 de la Biblioteca Histórica «Marqués de Valdecilla» de la Universidad Complutense de Madrid, f. ${ }^{\circ}$ 49r. Cf. F. J. del BARCo del BARCo, Catálogo de manuscritos hebreos de la Comunidad de Madrid, vol. I (Madrid 2003), pág. 154, y vol. III (Madrid 2006), pág. 161. Asimismo, aparece en el colofón parcial del ms. 592 de la Biblioteca de la Universidad de Salamanca, f. ${ }^{\circ}$ 112r; $c f$. J. Llamas, «Los manuscritos hebreos de la Universidad de Salamanca», Sef 10 (1950), págs. 263-279: 269. 
Adolf Neubauer ${ }^{4}$, basándose en la colaboración de Alfonso de Zamora en la columna de Targum de la Políglota Complutense, así como en los elogios que contiene la introducción aramea al Cardenal «Ximenez [de Cisneros] (...) as well as [Pablo] Coronel», también atribuyó el texto de dicha introducción o prólogo -que publicó con gran competencia- a Alfonso de Zamora.

Este prólogo arameo de Alfonso de Zamora, que yo sepa, nunca ha sido traducido, así que me propuse dar una versión española basándome en un principio en el texto publicado por Neubauer, que en conjunto me parecía bastante bueno, siendo necesario advertir que es mejor el texto publicado en $J Q R$, que el del $B R A H$, pues en este último se han deslizado algunas erratas de imprenta ${ }^{5}$.

Con todo, me fue necesario resolver ciertas dudas recurriendo a una excelente reproducción digital en color del ms. Or. 645, f. 110r que me hizo llegar la Biblioteca de la Universidad de Leiden, a cuyos trabajadores, y muy especialmente a la Sra. Dña. Silvia Compaan-Vermetten, encargada de las Special Collections de la Leiden University Library, quiero agradecer aquí públicamente su eficiente ayuda, así como su generosidad por el permiso para reproducir tan magnífica copia digital.

Dicha reproducción digital del ms. Or. 645, f. ${ }^{\circ}$ 110r (olim Warner 65 F) permite ver una hoja de pergamino ( $\mathrm{Cod}$. Chart. $4^{\circ}$ ), algo deteriorada en todos sus bordes, en cuyo margen superior izquierdo aparecen dos anotaciones de antiguos bibliotecarios:

La primera anotación, algo más desvaída que la segunda, se encuentra en la esquina superior izquierda y consiste en la cifra en números arábigos «110». Se diría que fue escrita a lápiz.

La segunda anotación fue escrita con tinta a continuación del número, y pone: «Warner $65 \mathrm{~F} »$. Se trata de la antigua signatura que hace referencia a la colec-

${ }^{4} C f$. A. Neubauer, «Alfonso de Zamora», JQR 7/3 (Apr. 1895), págs. 389-417: 410 y ss., n. ${ }^{\circ}$ de serie XIII, y corregido y aumentado en el BRAH 27 (Jul.-Sept. 1895), págs. 193-213: 206 y ss., n. ${ }^{\circ}$ de serie XIV.

${ }^{5}$ En efecto, aunque $B R A H$ en ocasiones corrige erratas de imprenta que se han deslizado en $J Q R$, especialmente en lo que se refiere a los nombres propios castellanos, añade sus propias erratas al componer los textos en grafía hebrea. Así, por ejemplo, en la línea 6 de la introducción aramea que nos ocupa, donde $J Q R$ pone correctamente ולמיכתב ('y escribir'), BRAH yerra al poner ולמכחב, y en la línea 12, donde $J Q R$ pone דאינון ('que ellos son') -sic pro- דאינין ('que ellas son'), BRAH pone דאינזין 
ción de manuscritos orientales del diplomático Levinus Warner (1619-1665), embajador holandés en Constantinopla.

El texto principal consta de treinta y tres líneas en la característica escritura cuadrada sefardí de Alfonso de Zamora, con las vocales, acentos y diacríticos, también propios suyos. De estas treinta y tres líneas, las dos primeras están redactadas en hebreo y las treinta y una restantes, en arameo. El texto, como ya se ha dicho, es un prólogo al Targum de los Profetas Posteriores, esto es, desde Isaías en adelante ( $c f$. líneas 30-31 de la introducción «....ahora comienzo / con las profecías de Isaías...»).

En el margen lateral izquierdo hay una anotación hebrea de cuatro líneas que corren paralelas al borde vertical del folio. Esta anotación, en escritura cursiva sefardí, sin vocalizar, a excepción de una sola palabra, es también de Alfonso de Zamora, pues la letra es similar a la cursiva de los reclamos de los finales de folio escritos por Alfonso de Zamora en su copia del Targum de los Profetas Posteriores -con la inclusión del Targum de Lamentaciones tras el Targum de Jeremías- conservada en el ms. BH 4 de la Biblioteca Histórica «Marqués de Valdecilla» de la Universidad Complutense de Madrid. Además, el contenido de esta anotación se refiere, al igual que el texto principal, al trabajo de copia del Targum a los Profetas encargado por la Universidad de Salamanca, ya que se trata de un borrador de las jaculatorias o doxologías (תפלות סופי הספרים) para los colofones parciales de los libros del Targum de Ezequiel, Oseas y Joel.

El Dr. Carlos Carrete Parrondo, Catedrático de Hebreo de la Universidad de Salamanca, tuvo la amabilidad de enviarme una copia de aquellos colofones parciales del manuscrito autógrafo de Alfonso de Zamora ms. M-3 (Est.-1, Cajón I-Núm. 2) de la Biblioteca de la Universidad de Salamanca que correspondían a los finales de los libros indicados en la anotación marginal anónima del ms. Or. 645, f. ${ }^{\circ}$ 110r de Leiden. Las coincidencias entre ambos grupos de colofones parciales son una nueva prueba de que Alfonso de Zamora fue el autor de estas notas que, puestas en limpio, hoy se conservan en Salamanca.

La gran calidad de la reproducción digital de la Universidad de Leiden permite ver además que este folio, antes de que se escribiesen en él el texto del prólogo y las anotaciones que he descrito, recibió por contacto de la tinta fresca de otro folio unas líneas rojas, a modo de caja de escritura, y unos rótulos, también rojos, que indicaban el principio del capítulo 57 del libro bíblico de Isaías, y su incipit hebreo. En efecto, con la ayuda de un espejo, 
y no sin dificultad, pude leer en la parte superior las siguientes dos líneas, la primera son abreviaturas latinas y la segunda letras cuadras hebreas:

$1^{\text {a) }}$ Esa. Cap. 57, que quiere decir 'Isa(ías), cap(ítulo) 57', y que es la forma de citar que se encuentra en la Biblia Políglota Complutense.

2a ras palabras de Is 57,1 . Estas palabras hebreas están vocalizadas y sobre la letra $h \hat{e}$ ' correspondiente al artículo determinado hebreo se ve claramente el muy característico diacrítico en forma de cuña que marca las letras serviles en la Biblia Políglota Complutense y en los manuscritos de Alfonso de Zamora con ella relacionados.

Serían, pues, también de Alfonso de Zamora estas anotaciones que, involuntariamente y por contacto, estropearon una hoja de pergamino en blanco. Una vez estropeado el pergamino, sería usado por el mismo Alfonso de Zamora como borrador para redactar los textos en escritura hebrea que pensaba incluir en lo que sería su «obra» o trabajo de copia del Targum a los Profetas destinado a la Universidad de Salamanca.

Aparentemente, Alfonso de Zamora escribió primero el texto más extenso, es decir, el de la introducción o prólogo a la copia del Targum. Después, aprovechó el margen lateral para el texto más breve, que contiene las jaculatorias o doxologías de los colofones parciales a los targumîn o targumes de Ezequiel, Oseas y Joel.

Carlos Carrete ${ }^{6}$ ha publicado noticias procedentes de los libros de claustros (L-C) conservados en el Archivo Universitario de Salamanca (AUS) que tratan del encargo que dicha Universidad hizo a Alfonso de Zamora, con la intermediación del maestro Pablo Coronel, para que copiase una versión de la Biblia «en caldeo», esto es un targum arameo. Entre otras interesantes informaciones, destacaré de forma muy resumida que, tras varios contactos previos, el 22 de marzo de 1533, los miembros del claustro de la Universidad de Salamanca «mandaron dar doze ducados para pagar a Çamora que escrive la Biblia en Alcalá» (AUS, L-C XI, f. ${ }^{\circ} 119 v$ ) y poco después aparece el siguiente aval firmado por «Paulo Coronel»:

maestre Pablo catedrático deste Estudio e universidad de Salamanca, se obligó por su persona e bienes mueble e rayzes, avidos e por aver...

${ }^{6}$ C. CARrete Parrondo, Hebraístas judeoconversos en la Universidad de Salamanca (Siglos XV-XVI) (Salamanca 1983), págs. 23-24. 
de que Çamora, veçino de la villa de Alcalá, enbiaría hecha [sic] obra a la dicha Universidad escripta de la dicha Bliblia [sic pro Biblia] todo lo que valga en quantía de doze ducados...; donde no, quél se obligava e obligó, como dicho es, de lo pagar por su persona e bienes... [AUS, L-C XI, fol. 123v] .

La Universidad de Salamanca pagó, pues, a Alfonso de Zamora, con la intermediación de Pablo Coronel, doce ducados por una copia del Targum arameo de la Universidad Complutense en 1533. Unos quince o dieciséis años antes, en un apunte contable complutense de tiempos del Cardenal Jiménez Cisneros aparece un tal «maestro Pablo», que posiblemente sea el mismo Pablo Coronel, ocupado también en un trabajo de copia de textos targúmicos con traducción latina:

Di al maestro Pablo dos myll y seteçientos y sesenta maravedís por razón de vna Biblia que hace escribir de caldeo y latín, en la cual hay cincuenta y nueve cuadernos y medio de cuatro pliegos cada cuaderno, y dáse ochenta maravedís por cada cuaderno de los cuáles tenía recibidos dos mil ${ }^{8}$.

Como es bien sabido, en el tomo I de la Biblia Políglota Complutense se incluyó el Targum arameo (Targum de Onqelos) al Pentateuco, junto con su traducción latina, pero en los demás libros de la Biblia Hebrea no se quiso incluir el texto targúmico por razones de polémica religiosa, porque, según se explicaba en el Prólogo al lector del tomo II de la misma Políglota,

la [versión] aramea en los demás libros (los que no pertenecen al Pentateuco) está corrompida en algunos pasajes y sembrada de fábulas y de meras simplezas de talmudistas, por lo que no es digna en absoluto de ser incluida entre los Libros Sagrados ${ }^{9}$.

Pese a lo anterior, a continuación, el Cardenal Cisneros afirma lo siguiente:

\footnotetext{
${ }^{7}$ Cf. Carrete Parrondo, Hebraístas judeoconversos, pág. 24, notas 85 y 86.

${ }^{8}$ Citado por Cecilia Fernández Fernández, «La labor educadora de Cisneros y la primera biblioteca del Renacimiento en España», Anales de Documentación 5 (2002), págs. 81-98: 89-90.

${ }^{9}$ Cf. Biblia Políglota Complutense, tomo II, Prologus ad lectorem, f. ${ }^{\circ} 2 \mathrm{r}$....Na $<m>$ Chaldaica [tra $<n>$ slatio] in caeteris libris (praeterq $<u e>$ in Pe $<n>$ tateucho) corrupta est aliquib $<$ us $>$ in locis \& fabulis merisq $<u e>$ Thalmudistaru $<m>$ nugis co $<n>$ spersa; indigna prorsus quae Sacris Codicibus inseratur.
} 
Con todo, ya que en algunos pasajes, donde la versión es literal y no está corrompida, se favorece admirablemente a la religión cristiana, atendiendo a esto, hicimos traducir del arameo al latín todos los restantes libros del Antiguo Testamento, y, cuidadosamente, copiados con su traducción latina, hicimos que fuesen guardados en la Biblioteca Pública de nuestra [i. e., de Cisneros] Universidad Complutense. ${ }^{10}$

De estas copias complutenses del Targum arameo con su traducción latina, en las que, por encargo del Cardenal Cisneros, trabajaron Alfonso de Zamora y Pablo Coronel ${ }^{11}$, proceden las copias que encargó la Universidad de Salamanca a las que hace referencia el manuscrito ms. Or. 645, f. ${ }^{\circ} 110 \mathrm{r}$ de la Biblioteca de la Universidad de Leiden que hoy nos ocupa.

Actualmente, se conservan en la Biblioteca Histórica «Marqués de Valdecilla», de la Universidad Complutense de Madrid dos manuscritos targúmicos con traducción latina: el ms. BH 4, fechado el 27 de julio de 1517, y el ms. BH 5, fechado el 8 de abril de $1517^{12}$.

Si bien sólo aparece el nombre de Alfonso de Zamora en el colofón hebreo del ms. BH 5 (f. ${ }^{\circ}$ 193r), es evidente por el tipo de letra, por el asunto y por las fechas que el colofón hebreo del ms. BH 4 (f. $288 \mathrm{v}$ ) también es del mismo autor.

En la Biblioteca Nacional de Madrid se encuentra otro manuscrito targúmico con traducción latina de Alfonso de Zamora. Se trata del ms. 7542, que contiene el Targum a los Profetas anteriores, incluyendo además, al modo cristiano, el targum de Rut tras el de Jueces. Tiene un colofón hebreo y otro castellano (f. $235 \mathrm{v}$ ). De este último entresacamos los siguientes

${ }^{10}$ Biblia Políglota Complutense, tomo II, Prologus ad lectorem, f. ${ }^{\circ}$ 2r: Verum quia quibusdam in locis vbi integra est littera \& incorrupta; miru $<m>$ in modo fauet Christianae religioni, id circo reliquos libros totius Veteris Testame $<n>$ ti e Chaldaica lingua in latina $<m>$ verti fecimus $\&$ dilige $<n>$ tissime $c u<m>$ sua latina traductione $c o<n>$ scriptos in publica $C o<m>$ plutensis nostrae Vniversitatis Bibliotheca reponi.

${ }^{11}$ Alfonso de Zamora atribuye a Pablo Coronel la traducción latina del Targum a los Profetas en el Prólogo que se conserva en el ms. Or.645, f. ${ }^{\circ}$ 110r: «Esta versión de la lengua de los romanos la compuso personalmente el [...] maestre Pablo Coronel...» (1. 23-26)

${ }^{12}$ Cf. del Barco del Barco, Catálogo de manuscritos hebreos, vol. 1, págs. 162-164 (ms. 4) y 165s. (ms. 5), con la advertencia de que yo he podido ver que en el colofón hebreo del ms. BH 4, a la fecha de אלף וחמש מאות, 'mil quinientos' se le añade en el margen interlineal superior, en letra microscópica, ויז' ('y 17'); de modo que la fecha de 1517, que ya se indicaba en el colofón latino, aparece también, en forma de añadido marginal que subsana la omisión previa, en hebreo. 
datos: « escripto por mano de alonso de çamora y fue acabado en el mes de março año mill y quinientos y treinta y tres para Don Antonio Ramirez de Haro, Abbad de Arvas ${ }^{13}$.

En la Biblioteca de la Universidad de Salamanca todavía se conserva parte de este trabajo del Targum a los Profetas encargado a Alfonso de Zamora. Siguiendo los datos proporcionados por Llamas ${ }^{14}$, creo que podríamos intentar reconstruir la siguiente secuencia:

$1^{\circ}$ ) Ms-M-1 (Est.-I-Cajón I-Núm.-I), escrito en pergamino, a doble columna, con iniciales, principios de libros y de capítulos en tinta roja, 261 folios, caja total: 320 x $210 \mathrm{~mm}$. Contiene el Targum arameo -y su traducción latina- a los llamados Profetas anteriores, esto es los libros de Josué, Jueces, 1 y 2 Samuel y 1 y 2 Reyes, con la inclusión de Rut, tras el libro de los Jueces.

$2^{\circ}$ ) Un manuscrito hoy perdido al que se alude al principio (f. ${ }^{\circ} 1 \mathrm{r}$ ) del ms. M-3 diciendo que se terminó el libro de Jeremías, contendría el Targum de Isaías y Jeremías, y posiblemente el Targum de Lamentaciones, tras el libro de Jeremias, y acaso, al comienzo del volumen, el prólogo de Alfonso de Zamora que nos ocupa aquí.

$3^{\circ}$ ) Ms-M-3 (Est.-I-Cajón I-Núm.-2), escrito en pergamino en la misma forma que M-1, 144 folios, caja total: 320 x $210 \mathrm{~mm}$. Contiene el Targum arameo -y su traducción latina- a Ezequiel y a los Doce Profetas Menores. Tiene un colofón en el que se indica que se terminó en el día «séptimo» (es decir, sábado), 3 de agosto del año 1532, por Alfonso de Zamora, en el lugar de Alcalá de Henares.

Además, se conserva en la biblioteca de la Universidad de Salamanca un Targum a los Hagiógrafos que es claramente continuación del trabajo del Targum a los Profetas encargado por la Universidad de Salamanca a Alfonso de Zamora. Se trata del Ms-M-2 (Est.-I-Cajón I-Núm.-3), escrito en pergamino, a doble columna, con iniciales, principios de libros y de capítulos en tinta roja, 229 folios, caja total: 320 × $210 \mathrm{~mm}$. Contiene el Targum arameo -y su traducción latina- a los libros de Ester, Job, Salmos, Proverbios, Eclesiastés y Cantar de los Cantares. No se incluye aquí Rut, que como hemos visto se había incluido tras el libro de Jueces en Ms-M-1 (Est.-I-Cajón I-Núm.-I), y tampoco se incluye el Targum de Lamentaciones, que es de suponer que iría tras el Targum de Jeremías en el volumen hoy perdido.

${ }^{13}$ Cf. del Barco del Barco, Catálogo de manuscritos hebreos, vol. 2, págs. 141s.

${ }^{14} C f$. Llamas, «Los manuscritos hebreos de la Universidad de Salamanca», págs. 270-274. 
Cabría la posibilidad de que en el ms. Or. 645 (olim Warner 65) de la Leiden University Library se hayan conservado más partes de ese volumen perdido del Targum de Isaías y Jeremías encargado por la Universidad de Salamanca a Alfonso de Zamora, aunque sólo sea en forma de borrador. Para intentar averiguarlo solicité un microfilm de todo el manuscrito, pero desgraciadamente, su mal estado de conservación hace imposible microfilmarlo antes de proceder a su restauración.

Volviendo al prólogo arameo de Alfonso de Zamora cuya traducción yo me había propuesto hacer, he de decir que, al colacionar la reproducción digital del manuscrito ms. Or. 645, f. ${ }^{\circ} 110 \mathrm{r}$ de la Leiden University Library con el texto de Neubauer publicado en $J Q R$, pude observar las siguientes divergencias ${ }^{15}$ :

En la 1.[ínea] 4 del manuscrito pone לקבליה y no לקיבליה.

En la 1. 5 del manuscrito parece poner די על לקליח separado, aunque también podría ir junto, como transcribe Neubauer.

En la 1. 12 del manuscrito pone el femenino דאינין y no el masculino דאינון

En la 1. 13 del manuscrito pone ולמילף, y no ולמולף.

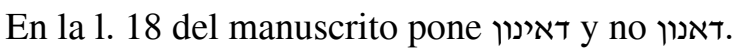

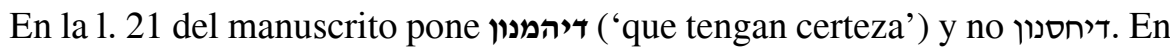

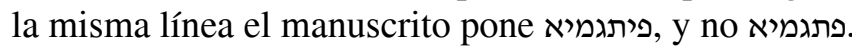

En la 1. 22 del manuscrito pone באתריה ('en su lugar'), y no באתרת.

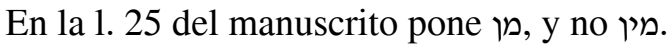

En la 1. 27 del manuscrito pone וספרא ספרארא, ע מספרא, En la misma línea del manuscrito pone סיפריא, y no ספריא.

En la 1. 29 del manuscrito parece poner דיהנון ('que obtengan provecho'), usando el mismo verbo que en la 1. 21, aunque tal vez pudiera leerse דיהגון ('que aprendan'); pero en ningún caso שאינון.

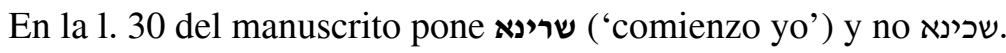

En la 1. 32 del manuscrito pone פיתגמין, y no פתגמין.

Para mayor comodidad de los lectores, daré a continuación el texto de la introducción indicando las líneas del manuscrito. Las dos primeras líneas, están redactadas en hebreo. El resto del texto, desde la línea 3 hasta el final, está redactado en arameo. Las líneas 23 a 26, que contienen el elogio a Pablo Coronel, al que se atribuye la autoría de la traducción latina del targum, pese a comenzar

${ }^{15}$ Es de advertir que las líneas del manuscrito no coinciden con las líneas del texto publicado por Neubauer, y que las variantes que me parecen relevantes por afectar al sentido las señalo con negrita. 
con un tipo de letra destacado, aparecen tachadas en el manuscrito, pero esa tachadura, que señalo mediante el subrayado, no impide leer el texto.

_ הקדמת מלאכת התרגום שכתבתי למדינת שאלאמאנקה. זבררי כותב הספר הזה לכל הקורא בו בדבר כל חוזה.

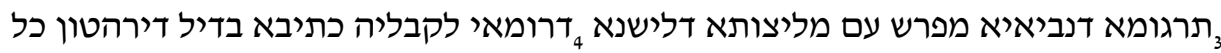

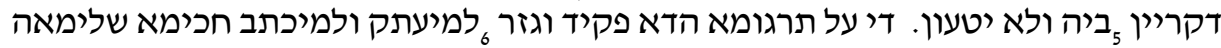

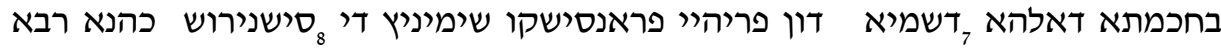

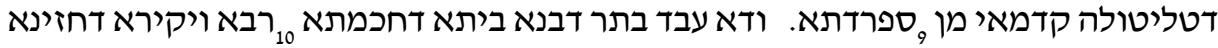

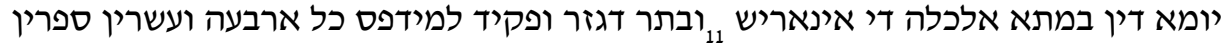

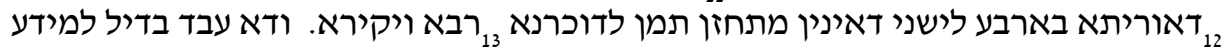

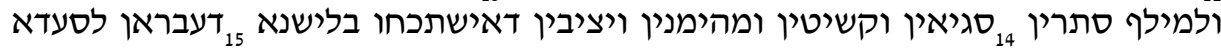

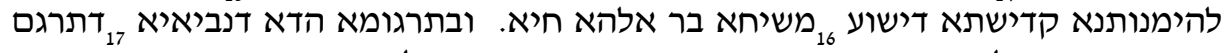
יהונתן ברעוזיאל אישתכחו פיתגמין דקשוט

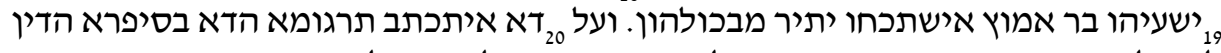

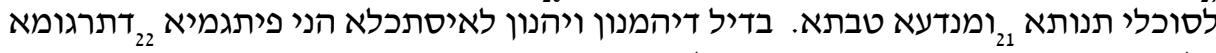
כל חד מנהון באתריה. ויטרון ומנות יתהון בליבהון.

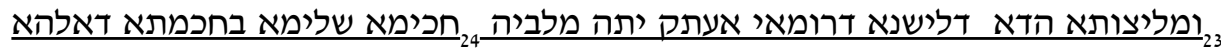

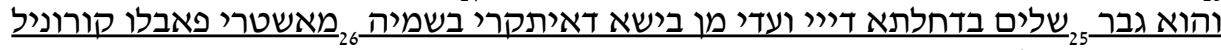
די שמעיה בכל ארעא.

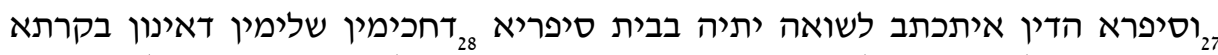

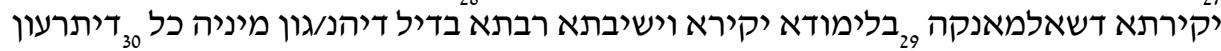

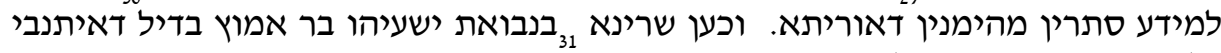

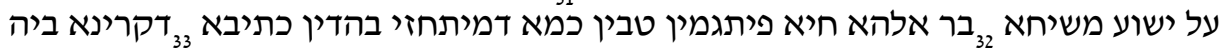

בדין אורחא.

He aquí mi traducción que he intentado que sea lo más literal y ajustada a las líneas que fuera posible sin que resultase excesivamente extraña al castellano actual:

[heb.] Prólogo de la obra del Targum que he escrito para la ciudad de Salamanca.

[heb.] ${ }_{2}$ Palabras del copista de este libro a todo aquel que lo lea por causa de Aquel que todo lo ve.

[aram.] ${ }_{3}$ Este Targum de los Profetas, explicado con la traducción en la lengua de los romanos [en columna] enfrentada, se escribió para que todos los que lo lean avancen rápidamente ${ }_{5} \mathrm{y}$ no yerren; ya que, acerca de este Targum, dio órdenes y mandó ${ }_{6}$ traducir[lo] y 


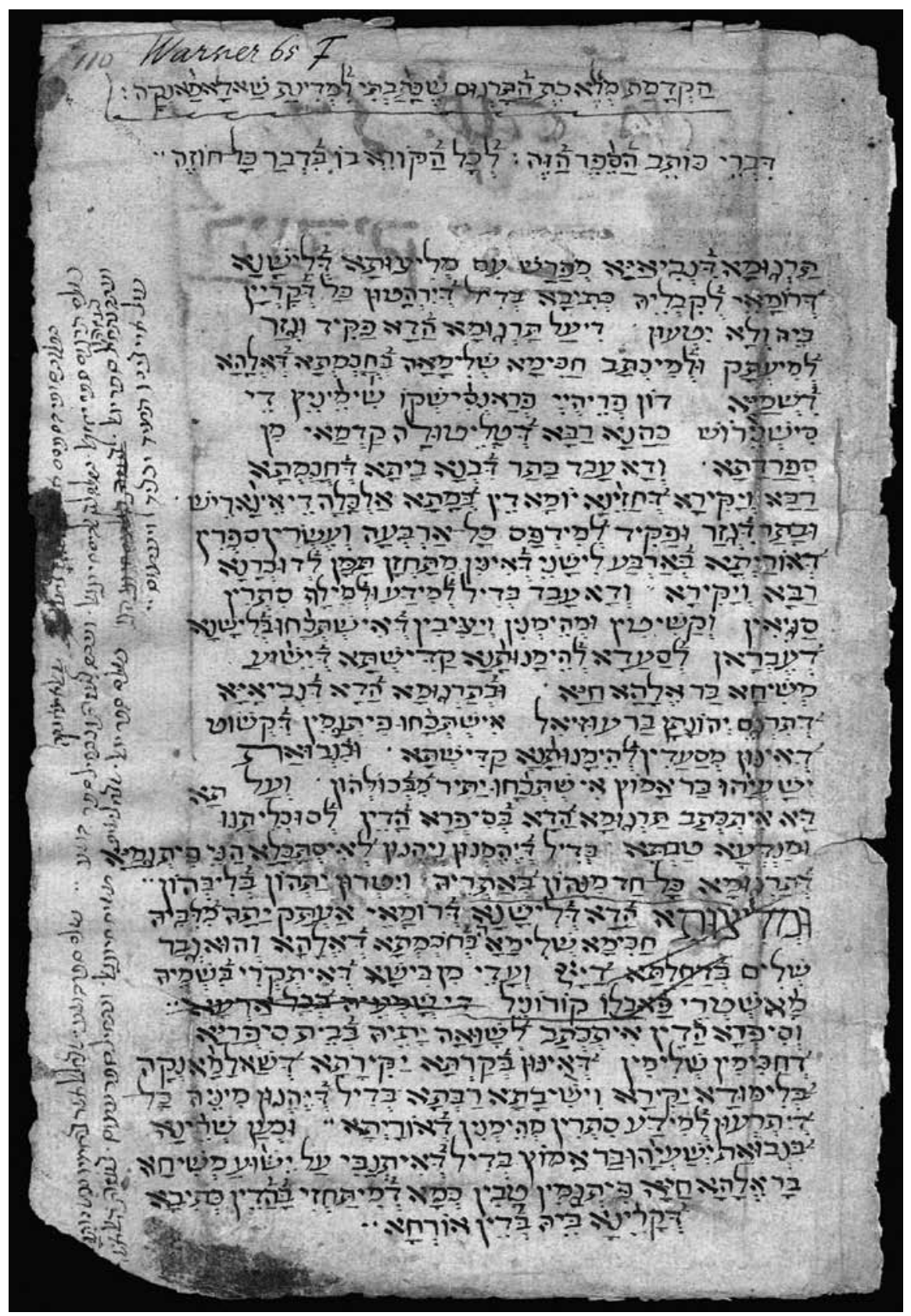

Fig. 1. Leiden University Library, ms. Or. 645, f. ${ }^{\circ} 110$ r. 
copiar[lo] el sabio perfecto en la ciencia del Dios ${ }_{7}$ de los Cielos, don frey $[\text { sic }]^{16}$ Francisco Ximénez de ${ }_{8}$ Cisneros, Arzobispo ${ }^{17}$ de Toledo, Primado de ${ }_{9}$ las Españas. ${ }^{18}$

Esto [lo] hizo después de construir la Universidad ${ }^{19}{ }_{10}$ grandiosa e ilustre que vemos hoy en la villa [de] Alcalá de Henares, ${ }_{11} \mathrm{y}$ después de mandar y dar orden de imprimir la totalidad de los veinticuatro libros ${ }_{12}$ de la Torá en cuatro lenguas, los cuales [libros] pueden verse allí para memorial ${ }_{13}$ magnífico y glorioso. Hizo esto para entender y enseñar arcanos ${ }_{14}$ múltiples, verídicos, fidedignos e irrefutables que se encuentran en la lengua ${ }_{15} \mathrm{de}[\mathrm{los}]$ hebreos para apoyar nuestra santa fe de Jesús, ${ }_{16}$ el Mesías, Hijo de Dios vivo [cf. Mat 16, 16].

En este Targum de los Profetas, ${ }_{17}$ que compuso Jonatán, hijo de Uzziel, se hallan cosas veraces ${ }_{18}$ que apoyan nuestra santa fe, pero en las profecías de ${ }_{19}$ Isaías, hijo de Amós, se encuentrán más que en cualquiera. Por ${ }_{20}$ esto se escribió este Targum en este libro para los que se encargan de la enseñanza ${ }_{21} \mathrm{y}$ de la buena ciencia, para que ellos tengan certeza y obtengan provecho al ver aquellas palabras ${ }_{22}$ del Targum, cada una de ellas en su lugar, y las guarden en su corazón.

${ }_{23}$ Esta versión de la lengua de los romanos la compuso personalmente ${ }^{20}{ }_{24}$ el sabio perfecto en la ciencia de Dios, que es [también] varón ${ }_{25}$ perfecto en el temor del Señor y que se aparta del mal, el cual tiene por nombre ${ }_{26}$ maestre Pablo Coronel, cuya fama [se extiendel por toda la tierra ${ }^{21}$.

${ }_{27}$ Este libro se escribió para colocarlo en la Biblioteca ${ }_{28}$ de los sabios perfectos que están en la gloriosa ciudad de Salamanca, ${ }_{29}$ en el ilustre estudio y gran academia, para que obtengan provecho ${ }^{22}$ de él todos ${ }_{30}$ los que quieran conocer los arcanos fidedignos de la Torá.

Y ahora comienzo ${ }_{31}$ con las profecías de Isaías, hijo de Amós, porque él profetizó sobre Jesús, el Mesías, ${ }_{32}$ Hijo de Dios vivo, cosas buenas, como se ve en este escrito, ${ }_{33}$ con el que yo invito [a seguir] por este camino.

Acaba aquí mi traducción de este documento arameo de Alfonso de Zamora que trata de la importancia del estudio del targum.

\footnotetext{
${ }^{16}$ Se usa el título más honorífico frey, פִִּ en vez de fray, en consideración a que el Cardenal Cisneros, en su calidad de Regente, era Gran Maestre de las Ordenes Militares.

${ }^{17}$ Lit. 'sumo sacerdote', kahanâ' [sic] rabbâ'.

${ }^{18}$ Lit. 'Primero de las Sefarades', qadma'y [sic] min sěfaradâtâ [sic].

${ }^{19}$ Lit. 'la casa de la sabiduría', bêtâ' [sic] dè-hokmĕtâ'.

${ }^{20}$ Lit., 'desde su corazón' (mi-libbêh).

${ }^{21}$ Las líneas 23 a 26 están marcadas y tachadas ligeramente, pero pueden leerse bien.

22 'Que obtengan provecho o se aprovechen', si leemos dĕ-yehenûn (sic) (cf. supra 1. 21); pero, si leemos deّ-yehegûn (sic), 'que aprendan'.
} 
En cuanto a la anotación hebrea en el margen lateral izquierdo, como se ha dicho más arriba, consta de cuatro líneas escritas en letra cursiva sefardí también de Alfonso de Zamora, y se se trata un borrador o apunte para poner determinados explicit en los finales de los libros de la copia manuscrita del Targum a los Profetas que le fue encargada por la Universidad de Salamanca. El texto hebreo es el siguiente:

תפלות סופי הספרים אנשר אעתיק?] במלא[כת] שאלאמאנקה

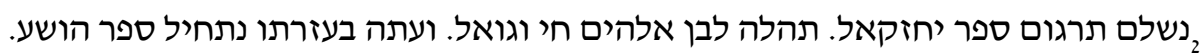

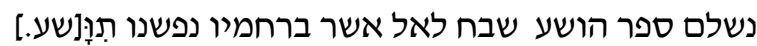

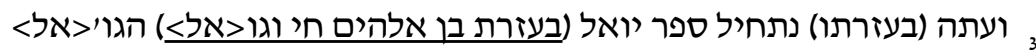

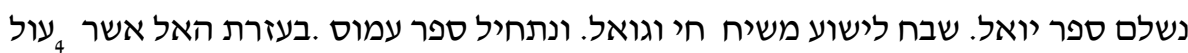

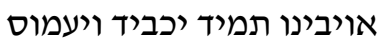

La línea primera, a modo de título, aunque se ha perdido parte del texto, parece decir:

${ }_{I}$ Jaculatorias de los finales de los libros q[ue ¿ copiaré?] en la ob[ra de] Salaman$c a$.

Las tres líneas restantes, sería los colofones parciales a determinados targumes a los Profetas:

${ }_{2}$ Se acabó ${ }^{23}$ el targum del libro de Ezequiel. ;Gloria al Hijo de Dios vivo y Redentor! $Y$ ahora con Su ayuda comenzamos el libro de Oseas.

Se acabó el libro de Oseas ;Alabado sea Dios por cuya misericordia nuestra alma se sa[lva]! ${ }_{3}$ Y ahora \{en el margen interlineal superior se añade: con Su ayuda $\}$ comenzamos el libro de Joel \{tachado: con la ayuda del Hijo de Dios vivo y Re $<$ dentor $>$ \} [ipor amor d?]el Re<dentor ${ }^{24}$. Se acabó el libro de Joel jAlabado sea Jesús, el Mesías

${ }^{23}$ Traduzco así, por parecerme más acorde con el castellano actual, aunque he de advertir que Alfonso de Zamora traduce nišlam por 'fue acabado' en sendos colofones bilingües suyos conservados en los mss. 4188 y 7542 de la Biblioteca Nacional de España, números 1 y 16 del Catálogo publicado por C. del Valle Rodríguez, Catálogo descriptivo de los manuscritos hebreos de la Biblioteca Nacional (Madrid 1986), págs. 27ss. y 89ss., que se corresponden con los números 103 y 88 del Catálogo de del BARCO del BARCO, Catálogo de manuscritos hebreos, vol. 2, págs. 169 y 141 , fechados respectivamente en 1523 y 1533.

${ }^{24}$ Según me informa por carta el Dr. Carlos Carrete, el ms. 3 de Salamanca, autógrafo de Alfonso de Zamora, pone en su colofón parcial de este lugar: ברחמי הגואל, 'por amor del Redentor'. 
encarnado y Redentor! Y ahora comenzamos el libro de Amós con la ayuda de Dios que ${ }_{4}$ siempre hace pesado y agrava el yugo de nuestros enemigos.

Como puede verse, se trata de unas jaculatorias de marcado carácter cristiano, en total consonancia con las múltiples expresiones religiosas formuladas en el prólogo arameo por Alfonso de Zamora.

A la vista de todo lo anterior, no cabe ninguna duda de que los textos hebreos y arameos que se conservan en el Leiden University Library, ms. Or. 645, f. ${ }^{\circ}$ 110r fueron escritos por Alfonso de Zamora, maestro regente de la Universidad Complutense en la entonces villa de Alcalá de Henares, entre los años 1532 y 1533.

Recibido: 20/09/2009

Aceptado: 15/10/2009 